\title{
Community Participation, Supports, and Barriers of School-Age Children With and Without Disabilities
}

\author{
Gary Bedell, PhD, ${ }^{a}$ Wendy Coster, $\mathrm{PhD},{ }^{\mathrm{b}}$ Mary Law, $\mathrm{PhD},{ }^{\mathrm{c}}$ Kendra Liljenquist, BS, \\ Ying-Chia Kao, MA, ${ }^{b}$ Rachel Teplicky, MSc, ${ }^{c}$ Dana Anaby, PhD, ${ }^{d}$ Mary Alunkal Khetani, ScD ${ }^{\mathrm{e}}$ \\ From ${ }^{a}$ the Department of Occupational Therapy, Tufts University, Medford, MA; ${ }^{b}$ Department of Occupational Therapy, Sargent College of \\ Rehabilitation Sciences, Boston University, Boston, MA; 'CanChild Centre for Childhood Disability Research and School of Rehabilitation \\ Sciences, McMaster University, Hamilton, ON, Canada; ${ }^{d}$ Department of Occupational Therapy, McGill University, Montreal, QC, Canada; and \\ ${ }^{e}$ Department of Occupational Therapy, Colorado State University, Fort Collins, CO.
}

\begin{abstract}
Objective: To examine patterns of community participation and environmental factors that affect community participation for school-age children with and without disabilities.

Design: Cross-sectional, descriptive, and exploratory study.

Setting: Parents from the United States and Canada completed the main outcome measure online in their homes or communities.

Participants: Parents $(\mathrm{N}=576)$ reported on their children aged 5 to 17 years with disabilities $(\mathrm{n}=282)$ and without disabilities $(\mathrm{n}=294)$.

Interventions: Not applicable.

Main Outcome Measure: Participation and Environment Measure for Children and Youth.

Results: Group differences in summary scores and many items were significant $(P<.001)$. Children with disabilities participated less frequently, were less involved, and had less environmental support in the community than children without disabilities. Parents of children with disabilities desired more change in their child's participation than parents of children without disabilities. Effect sizes for summary scores were moderate to very large $\left(n^{2} \mathrm{p}\right.$ from .11-.40), with the largest group difference found in environment scores. Overall, the largest group differences in participation were in "unstructured physical activities" and "getting together with other children"-also the 2 areas where parents of children with disabilities most frequently desired change. The largest differences in environmental impact were in physical, social, and cognitive activity demands and availability/adequacy of programs and services.

Conclusions: Results provide insights about where greater efforts are needed to support community participation of school-age children with disabilities. Further study with a more diverse sample in terms of race/ethnicity, family income/education levels, and geographic region is needed to determine the extent to which results may be generalized.
\end{abstract}

Archives of Physical Medicine and Rehabilitation 2013;94:315-23

(C) 2013 by the American Congress of Rehabilitation Medicine

Participation in activities that provide a sense of accomplishment and enjoyment during childhood and youth helps to foster positive development into adulthood. ${ }^{1-5}$ Participation has been shown to be an indicator of overall health and well-being across the lifespan and has been described as a key rehabilitation outcome. ${ }^{5-8}$

Supported by the US Department of Education, National Institute on Disability and Rehabilitation Research, to Boston University (grant no. H133G070140).

No commercial party having a direct financial interest in the results of the research supporting this article has or will confer a benefit on the authors or on any organization with which the authors are associated.
However, children with disabilities are often restricted in their participation. ${ }^{7,9-11}$ Most research on participation of children with disabilities has focused on children and youth with cerebral palsy (CP) ${ }^{1,10-14}$ and acquired brain injury (ABI). ${ }^{9,15-17}$ Findings from this research demonstrate that children with disabilities often participate in and enjoy a wide range of activities but participate less frequently than children without disabilities in many of these activities. Findings also indicate that children with disabilities are often more restricted when participating in the community than at home or at school. ${ }^{15,18,19}$ 
Community participation of children with disabilities is influenced by features of the physical, social, and attitudinal environment. $^{7,15,16,18,20-25}$ It can be affected by the child's immediate environment (eg, built environment, transportation, programs and services, social supports, actions and attitudes of others) and the more indirect environment (eg, institutional policies and procedures). ${ }^{15,16,18,19,23-26}$ While most research has focused on environmental barriers that hinder participation, it is also important to examine environmental supports because of their positive direct and indirect effects on enabling children's participation. ${ }^{19,20-22,26,27}$ Large-scale studies conducted across Europe have found country- and district-wide differences in policies, resources, and accessibility that differentially affect community participation of children with $\mathrm{CP}$, with greater access and resources associated with greater extent of participation. ${ }^{20,22,23,27}$

Environmental barriers often are more frequently encountered and more challenging to predict and manage in the community than at home or at school. ${ }^{15,18,19}$ Lack of information, programs, and services as well as problems with government policies, social supports, and attitudes of others in the community are commonly reported as environmental barriers affecting children with $\mathrm{ABI}$ and their families. ${ }^{15,16,21,26}$ Inadequate social supports, negative attitudes, and inaccessible physical environments were identified in a systematic review as the most commonly reported barriers to the participation of children with $\mathrm{CP} .{ }^{11}$ Lower family income has been associated with lower frequency and diversity of participation of children with CP and other physical disabilities.,18,28,29 No studies were found that compared patterns of environmental factors affecting children with and without disabilities. However, there is some evidence to suggest that families of children with disabilities might have less income due to additional costs associated with the child's disability. ${ }^{18,23,30,31}$

The purpose of this study was to (1) examine patterns of community participation and environmental factors that affect community participation for school-age children with a broad range of disabilities and (2) draw comparisons with school-age children without disabilities.

\section{Methods}

\section{Recruitment, sampling, and data collection}

This study examined data that were collected via an online survey used to test a newly developed instrument, the Participation and Environment Measure for Children and Youth (PEM-CY). Recruitment for the original study occurred from May to October $2010 .{ }^{32,33}$ Parents/caregivers of children with and without disabilities residing in Canada and the United States were invited to participate. Recruitment assistance from colleagues was requested by phone, e-mail, in person at conferences, and through Listservs or in professional organization newsletters. Research staff provided program directors and staff with printed and Webbased materials to post at their agency and distribute to families.

\section{List of abbreviations: \\ ABI acquired brain injury \\ ANCOVA analysis of covariance \\ CP cerebral palsy \\ PEM-CY Participation and Environment Measure for Children and Youth}

Participants were eligible if they were a parent or legal guardian of a child between 5 and 17 years of age and they were able to read English. Ethical approval was received from the 3 participating universities.

Parents were directed to a secure website to access the PEM-CY and were instructed to insert an assigned username and password to enter the survey site. Upon entry, parents had to confirm their eligibility to participate and provide informed consent. Parents were asked to select only 1 child to report on when they had multiple children who fit the inclusion criteria and then completed a demographic questionnaire and the PEM-CY on this 1 child.

\section{Instrument}

The PEM-CY is a parent-report instrument that examines participation and environment factors that affect the participation of school-age children (5-17y of age) across 3 settings: home, school, and community. ${ }^{19,32,33}$ It was initially designed as an online survey for use in population-based research. ${ }^{32,33}$

PEM-CY participation items for each setting represent broad types of activities typically performed in that setting. For each activity type, parents are asked (a) how frequently their child participates (never $=0$ to daily $=7$ ); (b) how involved their child is while participating (minimally $=1$ to very $=5$ ); and (c) whether they desire change in their child's participation (no or yes; if yes, parents identify where change is desired: frequency, involvement, and/or variety). Parents are then asked whether certain features of the environment help or make it harder for their child to participate in activities in that setting (not an issue, usually helps, sometimes helps/sometimes makes harder, usually makes harder) or about perceived adequacy/availability of resources (not needed, usually yes, sometimes yes/sometimes no, usually no).

PEM-CY summary scores and items pertaining to the community setting were examined in this study. The 5 summary scores examined are described in table 1. Prior research indicated that test-retest reliability was moderate to excellent for the community summary scores (intraclass correlations ranging from .66 to .96) and for individual items (percent agreements ranging from .73 to .93$).^{32}$ Internal consistency was reported to be moderate to good for the community summary scores (Cronbach $\alpha$ ranging from .70 to .83$){ }^{32}$

\section{Data analysis}

Analyses of variance and analyses of covariance (ANCOVA) were used to compare differences in the PEM-CY community participation and environment summary scores and between children with and without disabilities. The child's age category and family income category were entered as covariates because of group differences on these variables in our sample. Partial eta squares $\left(n^{2} \mathrm{p}\right)$ were used to examine effect sizes specific to differences in the disability group according to Kirk's classification $($ small $=.01-.05$; moderate $=.06-.13$; large $\geq .14) .{ }^{34}$

ANCOVAs (adjusting for age and income category) and partial eta squares were also used to compare mean item-level scores for participation frequency and involvement between children with and without disabilities. Chi-square analyses were used to compare the percentage of parents in each group who responded (a) "never" for participation frequency items; (b) "yes" for desired 
Table 1 Descriptions of PEM-CY community summary scores

1. Participation frequency: Average of all ratings except those to which parent responded "never" for frequency. Higher scores reflect greater frequency.

2. Percent never participates: Number of items answered "never" divided by the total number of items rated and then multiplied by 100 . Higher scores reflect greater number of activities that child never participates in.

3. Involvement: Average of all ratings except those to which parent responded "never" for frequency. Higher scores reflect greater involvement.

4. Percent that parents desired change (indicator of overall satisfaction with child's participation): Number of "Yes, change" responses divided by the total number of items rated and then multiplied by 100 . Higher scores reflect greater number of activities that parents desire change in their child's participation.

5. Percent total environmental supportiveness: Sum of ratings divided by the number of items rated multiplied by 100 . Higher scores reflect greater environmental supportiveness. NOTE. A 3-point rating scale was first created by collapsing the 5 categories used to assess both "features of environment that help/make it harder" and "perceived adequacy/availability of resources" ( $1=$ Usually makes harder/Usually no; $2=$ Sometimes helps/makes harder or Sometimes yes/no; $3=$ Usually helps/Usually yes or Not an issue/Not needed).

change items; (c) "usually makes harder," "usually helps," and "not an issue" to environmental support and barrier items; and (d) "usually, no," "usually, yes," and "not needed" to availability/ adequacy of resources items. Because of multiple comparisons, Bonferroni corrections were made to significance levels by dividing .05 by the number of comparison tests conducted for each set of analyses.

\section{Results}

\section{Participants}

The PEM-CY was completed online by 576 parents and guardians of children with and without disabilities residing in the United States and Canada. The groups were similar in a number of demographic characteristics (table 2). Most respondents were mothers, had high levels of education (most graduated from college or graduate school), and lived in similar types of communities (most resided in the Northeast, United States, and Southern Ontario, Canada). There were approximately equal numbers of children with disabilities $(n=282)$ and without disabilities $(n=294)$. Most children were white, non-Hispanic $(n=466 ; 81 \%)$ followed by black $(n=19 ; 3 \%)$, South Asian $(n=15 ; 2.5 \%)$, Hispanic/Latino $(n=10 ; 2 \%)$, other $(n=8 ; 1 \%)$, or not reported $(n=46 ; 7 \%)$. More children without disabilities were younger than 12 years $(P<.002)$ and lived in households with incomes of more than $\$ 80,000(P<.001)$. Children with disabilities had a broad range of diagnoses and disabling conditions (table 3).

\section{Community summary scores}

Significant group differences with and without adjusting for age and family income category $(P<.001)$ were observed for all PEM-CY participation and environment summary scores. Unadjusted means were very similar to ANCOVA adjusted means, so unadjusted means are presented with their corresponding SDs (table 4). For example, differences between adjusted and unadjusted means ranged from .01 to .03 for "frequency and involvement," .32 to .34 for "percent never participates," .89 to .94 for "percent desires change," and .68 to .73 for "percent environmental supportiveness" scores. Children with disabilities participated less frequently and had lower levels of involvement in community activities than children without disabilities. Parents of children with disabilities also more frequently desired change in their child's community participation and reported lower overall environmental supportiveness of the community than parents of children without disabilities. Effect sizes $\left(n^{2} \mathrm{p}\right)$ comparing the magnitude of differences specific to disability ranged from moderate to very large, with the largest effect size found in overall environmental supportiveness.

Table 2 Participant characteristics

\begin{tabular}{|c|c|c|}
\hline Variable & $\begin{array}{l}\text { With Disability } \\
(\mathrm{n}=282)\end{array}$ & $\begin{array}{l}\text { Without Disability } \\
(n=294)\end{array}$ \\
\hline \multicolumn{3}{|l|}{ Child sex } \\
\hline Male & $166(59)$ & $145(49)$ \\
\hline Female & $116(41)$ & $149(51)$ \\
\hline Child age $(y)^{*}$ & $\begin{array}{c}\text { Mean }=11.7 \\
S D=3.11\end{array}$ & $\begin{array}{c}\text { Mean }=10.6 \\
S D=2.98\end{array}$ \\
\hline Younger than 12 & $140(50)$ & $183(62)$ \\
\hline 12 and older & $142(50)$ & $111(38)$ \\
\hline \multicolumn{3}{|l|}{ Respondent relation with child } \\
\hline Mother & $258(92)$ & $261(90)$ \\
\hline Father & $18(6)$ & $26(9)$ \\
\hline Guardian & $6(2)$ & $3(1)$ \\
\hline \multicolumn{3}{|l|}{ Respondent age (y) } \\
\hline $30-39$ & $89(32)$ & $103(35)$ \\
\hline $40-49$ & $158(57)$ & $161(55)$ \\
\hline $50-59$ & $29(10)$ & $24(8)$ \\
\hline \multicolumn{3}{|l|}{ Respondent education } \\
\hline High school or less & $20(7)$ & $8(3)$ \\
\hline $\begin{array}{l}\text { Some college/university or } \\
\text { technical training }\end{array}$ & $48(17)$ & $31(11)$ \\
\hline $\begin{array}{l}\text { Graduated college/ } \\
\text { university }\end{array}$ & $144(51)$ & $136(46)$ \\
\hline Graduate degree & $70(25)$ & $118(40)$ \\
\hline \multicolumn{3}{|l|}{ Family income $(\$)^{*}$} \\
\hline$<40,000$ & $50(18)$ & $15(15)$ \\
\hline $40,000-80,000$ & $72(27)$ & $65(23)$ \\
\hline$>80,000$ & $151(55)$ & $207(72)$ \\
\hline \multicolumn{3}{|l|}{ Country of residence } \\
\hline United States & $87(31)$ & $126(43)$ \\
\hline Canada & $195(69)$ & $168(57)$ \\
\hline \multicolumn{3}{|l|}{ Type of community } \\
\hline Major urban & $115(42)$ & $142(49)$ \\
\hline Suburban & $95(34)$ & $97(34)$ \\
\hline Small town & $53(19)$ & $37(13)$ \\
\hline Rural & $13(5)$ & $11(4)$ \\
\hline
\end{tabular}


Table 3 Parent-reported diagnoses of children with disabilities

\begin{tabular}{lcc}
\hline & \multicolumn{2}{c}{$\mathrm{n}(\%)$} \\
\cline { 2 - 3 } Diagnosis* $^{*}$ & $71(25.6)$ & $72(25.5)$ \\
\hline Developmental delay & $22(7.9)$ & $36(12.8)$ \\
Intellectual delay & $8(2.9)$ & $11(3.9)$ \\
Hearing impairment & $23(8.3)$ & $60(21.3)$ \\
Speech/language impairment & $4(1.4)$ & $21(7.4)$ \\
Vision impairment & $24(8.7)$ & $33(11.7)$ \\
Emotional impairment & $53(19.1)$ & $100(35.5)$ \\
Orthopedic impairment & $20(7.2)$ & $47(16.7)$ \\
Autism spectrum disorder & $15(5.4)$ & $40(14.2)$ \\
Attention deficit disorder & $0(0.0)$ & $12(4.3)$ \\
Traumatic brain injury & $8(2.9)$ & $33(11.7)$ \\
Learning disability & $12(4.3)$ & $50(17.7)$ \\
Health impairment & $2(0.7)$ & $34(12.1)$ \\
Multiple disabilities & $15(5.4)$ & \\
Other &
\end{tabular}

* Parents could report up to 3 diagnoses or conditions.

\section{Community participation items}

Table 5 includes results that describe and compare participation at the item level for children with and without disabilities. Results from chi-square analyses are reported for the percentage of children who never participated (Never Participates) and the percentage of parents who desired change in their child's participation (Desires Change). Results from ANCOVA are reported for the mean participation frequency and involvement scores. Unadjusted means were very similar to ANCOVA adjusted means, and so unadjusted means are presented with their corresponding SDs. For example, differences between adjusted and unadjusted frequency and involvement item means ranged from .00 to .14 , with the majority ranging from .01 to .05 . The effect sizes $\left(n^{2} \mathrm{p}\right)$ in table 5 indicate the magnitude of differences specific to disability.

The percentage of children with disabilities who never participated was significantly higher than that of children without disabilities for all items except neighborhood outings and religious/ spiritual activities (see table 5). The largest group differences found in the percentage of "never participates" responses included getting together with other children in the community, organized and unstructured physical activities, and community events. In addition, more than $40 \%$ of the children in both groups reportedly never participated in working for pay, organization-leadership activities, classes/lessons, and religious/spiritual activities.
Children with disabilities had significantly lower mean participation frequency scores than children without disabilities in 6 of the 10 activities when adjusting for age and income category. Activities with the largest group differences (moderate effect sizes) were getting together with other children $\left(n^{2} \mathrm{p}=.08\right)$ and unstructured and organized physical activity $\left(n^{2} \mathrm{p}=.06\right)$. No significant differences were found for classes/lessons, organization-leadership activities, working for pay, and religious/spiritual activities. The item with the highest mean participation frequency for children with disabilities was neighborhood outings compared with unstructured physical activities for children without disabilities. The item with the lowest mean participation frequency was overnight visits for both groups.

Children with disabilities also had significantly lower mean involvement scores than children without disabilities for 8 of the 10 activities when adjusting for age and income category. However, these differences were less attributed to disability for some of the more structured activities in this list (working for pay, classes and lessons, organizational-leadership activities), as shown by the negligible effect sizes. The activities with the largest group differences were unstructured physical activity $\left(n^{2} \mathrm{p}=.10\right)$, getting together with other children $\left(n^{2} \mathrm{p}=.09\right)$, and community events $\left(n^{2} \mathrm{p}=.09\right)$. No significant group differences were found for classes/lessons and religious/spiritual activities. The item with the highest mean involvement for children with disabilities was overnight visits compared with both overnight visits and getting together with other children in the community for children without disabilities. The lowest mean involvement score was religious/ spiritual activities for both groups.

More parents of children with disabilities than parents of children without disabilities desired change in their child's participation for all items. Significant group differences were found for all items except religious activities and working for pay. For parents of children with disabilities, unstructured physical activities and getting together with other children were the areas with the highest percentage of parents desiring change and working for pay was the area with the lowest percentage. For parents of children without disabilities, unstructured physical activities was the area in which the greatest percentage of parents desired change and overnight visits was the area with the lowest percentage.

\section{Community environment items}

\section{Extent of barriers and supports}

Significantly more parents of children with disabilities than parents of children without disabilities reported that the environment "usually made it harder" for their child to participate (table 6). Areas identified as the greatest barriers for children with

Table 4 Differences in community participation and environment summary scores

\begin{tabular}{|c|c|c|c|c|}
\hline Community Summary Scores & With Disability & Without Disability & ANCOVA $_{d f}$ & $n^{2} p$ \\
\hline Percent never participates & $41.49 \pm 20.07$ & $23.22 \pm 14.70$ & $F_{3,476}=116.17^{*}$ & .20 \\
\hline Participation frequency & $3.79 \pm 0.92$ & $4.43 \pm 0.69$ & $\mathrm{~F}_{3,475}=58.15^{*}$ & .11 \\
\hline Level of involvement & $3.55 \pm 0.93$ & $4.17 \pm 0.54$ & $F_{3,475}=70.13^{*}$ & .13 \\
\hline Percent that parents desired change & $62.68 \pm 25.85$ & $38.02 \pm 25.97$ & $F_{3,476}=86.19^{*}$ & .15 \\
\hline Percent total environmental supportiveness & $66.32 \pm 14.25$ & $88.20 \pm 10.82$ & $F_{3,462}=306.19^{*}$ & .40 \\
\hline
\end{tabular}

NOTES. Values in the first 2 columns are mean \pm SD. $n^{2} p=$ Partial eta squares (effect sizes) are reported only for differences related to disability and are rounded to 2 decimal points (effect sizes are small $=.01-.05$; moderate $=.06-.13$; large $\geq .14$ ). ${ }^{34}$

${ }^{*} P<.001$ for the total model based on ANCOVAs adjusting for child age and family income category (Bonferroni adjustment of the significance level was set at $P<.01)$. 
Table 5 Differences in community participation items

\begin{tabular}{|c|c|c|c|c|c|c|c|c|c|c|c|c|}
\hline \multirow[b]{2}{*}{ Items } & \multicolumn{3}{|c|}{ Never Participates, $\mathrm{n}(\%)^{*}$} & \multicolumn{3}{|c|}{ Frequency, Mean $\pm \mathrm{SD}^{\dagger}$} & \multicolumn{3}{|c|}{ Involvement, Mean $\pm \mathrm{SD}^{\dagger}$} & \multicolumn{3}{|c|}{ Desires Change, $\mathrm{n}(\%)^{*}$} \\
\hline & $\begin{array}{l}\text { With } \\
\text { Disability }\end{array}$ & $\begin{array}{l}\text { Without } \\
\text { Disability }\end{array}$ & $P$ & $\begin{array}{l}\text { With } \\
\text { Disability }\end{array}$ & $\begin{array}{l}\text { Without } \\
\text { Disability }\end{array}$ & $P\left(n^{2} \mathrm{p}\right)$ & $\begin{array}{l}\text { With } \\
\text { Disability }\end{array}$ & $\begin{array}{l}\text { Without } \\
\text { Disability }\end{array}$ & $P\left(n^{2} \mathrm{p}\right)$ & $\begin{array}{l}\text { With } \\
\text { Disability }\end{array}$ & $\begin{array}{l}\text { Without } \\
\text { Disability }\end{array}$ & $P$ \\
\hline 1. Neighborhood outings & $2(1)$ & $1(0.5)$ & .522 & $4.89 \pm 1.40$ & $5.34 \pm 0.99$ & $.001(0.03)$ & $3.61 \pm 1.22$ & $4.19 \pm 0.84$ & $.001(0.07)$ & $131(56)$ & $54(21)$ & .001 \\
\hline 2. Community events & $43(18)$ & $12(5)$ & .001 & $2.84 \pm 1.44$ & $3.29 \pm 1.51$ & $.003(0.02)$ & $3.44 \pm 1.29$ & $4.19 \pm 0.93$ & $.001(0.09)$ & $172(73)$ & $90(36)$ & .001 \\
\hline $\begin{array}{l}\text { 3. Organized physical } \\
\text { activity }\end{array}$ & $87(37)$ & $24(10)$ & .001 & $4.64 \pm 1.63$ & $5.38 \pm 1.42$ & $.001(0.06)$ & $3.87 \pm 1.29$ & $4.39 \pm 0.88$ & $.001(0.06)$ & $162(69)$ & $97(39)$ & .001 \\
\hline $\begin{array}{l}\text { 4. Unstructured physical } \\
\text { activities }\end{array}$ & $55(24)$ & $5(2)$ & .001 & $4.46 \pm 1.85$ & $5.41 \pm 1.42$ & $.001(0.06)$ & $3.42 \pm 1.26$ & $4.24 \pm 0.87$ & $.001(0.10)$ & $181(78)$ & $137(55)$ & .001 \\
\hline 5. Classes and lessons & $156(66)$ & $102(41)$ & .001 & $4.43 \pm 1.53$ & $4.43 \pm 1.71$ & $.163(0.00)$ & $3.92 \pm 0.94$ & $4.16 \pm 1.06$ & $.021(0.01)$ & $165(71)$ & $130(52)$ & .001 \\
\hline $\begin{array}{l}\text { 6. Organizations, groups, } \\
\text { clubs, volunteer, or } \\
\text { leadership activities }\end{array}$ & $171(73)$ & $143(57)$ & .001 & $3.92 \pm 1.45$ & $3.87 \pm 1.54$ & $.832(0.00)$ & $3.63 \pm 1.04$ & $4.01 \pm 1.0$ & $.002(0.01)$ & $162(69)$ & $114(46)$ & .001 \\
\hline $\begin{array}{l}\text { 7. Religious or spiritual } \\
\text { gatherings and } \\
\text { activities }\end{array}$ & $119(51)$ & $99(40)$ & .016 & $3.64 \pm 1.60$ & $4.17 \pm 1.60$ & $.025(0.04)$ & $2.91 \pm 1.28$ & $3.17 \pm 1.18$ & $.166(0.01)$ & $111(48)$ & $99(40)$ & .087 \\
\hline $\begin{array}{l}\text { 8. Getting together } \\
\text { with other children } \\
\text { in the community }\end{array}$ & $73(31)$ & $8(3)$ & .001 & $3.88 \pm 1.75$ & $4.96 \pm 1.61$ & $.001(0.08)$ & $3.77 \pm 1.13$ & $4.45 \pm 0.80$ & $.001(0.09)$ & $177(77)$ & $86(35)$ & .001 \\
\hline 9. Working for pay & $198(85)$ & $154(62)$ & .001 & $3.86 \pm 1.87$ & $3.76 \pm 1.76$ & $.416(0.00)$ & $3.74 \pm 1.40$ & $3.68 \pm 1.09$ & $.001(0.00)$ & $89(39)$ & $80(34)$ & .239 \\
\hline $\begin{array}{l}\text { 10. Overnight visits } \\
\text { or trips }\end{array}$ & $71(31)$ & $37(15)$ & .001 & $2.31 \pm 1.17$ & $2.61 \pm 1.30$ & $.001(0.03)$ & $4.11 \pm 0.95$ & $4.45 \pm 0.77$ & $.001(0.03)$ & $120(52)$ & $53(22)$ & .001 \\
\hline
\end{tabular}

NOTE. $n^{2} p=$ Partial eta squares (effect sizes) are reported only for differences related to disability and are rounded to 2 decimal points (effect sizes are small $=.01-.05 ;$ moderate $=.06-.13 ;$ large $\geq .14$ ). ${ }^{34}$

* Based on chi-square analyses (Bonferroni adjustment of the significance level was set at $P<.005$ ).

Based on analysis of covariance (ANCOVA) adjusting for child's age and family income category (Bonferroni adjustment of the significance level was set at $P<.005$ ). 
Table 6 Differences in community environment items: supports and barriers

\begin{tabular}{|c|c|c|c|c|c|c|c|c|c|}
\hline \multirow[b]{2}{*}{ Items } & \multicolumn{3}{|c|}{ Usually Harder } & \multicolumn{3}{|c|}{ Usually Helps } & \multicolumn{3}{|c|}{ Not an Issue } \\
\hline & $\begin{array}{l}\text { With } \\
\text { Disability }\end{array}$ & $\begin{array}{l}\text { Without } \\
\text { Disability }\end{array}$ & $P^{*}$ & $\begin{array}{l}\text { With } \\
\text { Disability }\end{array}$ & $\begin{array}{l}\text { Without } \\
\text { Disability }\end{array}$ & $P^{*}$ & $\begin{array}{l}\text { With } \\
\text { Disability }\end{array}$ & $\begin{array}{l}\text { Without } \\
\text { Disability }\end{array}$ & $P^{*}$ \\
\hline 1. Physical layout & $66(29)$ & $10(4)$ & .001 & $14(6)$ & $16(7)$ & .833 & $93(40)$ & $202(82)$ & .001 \\
\hline 2. Sensory quality & $43(19)$ & $6(2)$ & .001 & $4(2)$ & $10(4)$ & .130 & $112(49)$ & $205(84)$ & .001 \\
\hline 3. Physical demands of activity & $107(47)$ & $5(2)$ & .001 & $8(3)$ & $8(3)$ & .897 & $62(27)$ & $210(86)$ & .001 \\
\hline 4. Cognitive demands of activity & 74 (33) & $4(2)$ & .001 & $6(3)$ & $10(4)$ & .365 & $87(38)$ & $214(88)$ & .001 \\
\hline 5. Social demands of activity & $103(46)$ & $10(4)$ & .001 & $12(5)$ & $24(10)$ & .065 & $56(25)$ & $169(70)$ & .001 \\
\hline 6. Relations with peers & $66(29)$ & $9(4)$ & .001 & $40(18)$ & $54(22)$ & .213 & $54(24)$ & $133(55)$ & .001 \\
\hline 7. Attitudes & $49(21)$ & $3(1)$ & .001 & $36(16)$ & $57(24)$ & .033 & $52(23)$ & $148(61)$ & .001 \\
\hline 8. Weather conditions & $79(34)$ & $5(2)$ & .001 & $7(3)$ & $12(5)$ & .298 & $73(32)$ & $156(64)$ & .001 \\
\hline 9. Safety & $39(17)$ & $14(6)$ & .001 & $17(7)$ & $29(12)$ & .096 & $140(61)$ & $174(72)$ & .013 \\
\hline
\end{tabular}

NOTE. Values are $n(\%)$.

* Based on chi-square analyses (Bonferroni adjustment of the significance level set at $P<.006$ ).

disabilities included physical, social, and cognitive activity demands and weather conditions.

Parents of children without disabilities more frequently reported that features of the environment usually helped their child's participation than parents of children with disabilities. However, no significant group differences were found. Areas identified as the greatest supports of children with disabilities included relationships with peers and attitudes of others. Significantly more parents of children without disabilities than parents of children with disabilities reported that each feature of the environment (except for safety) was "not an issue" for their child. However, many parents of children with disabilities also reported "not an issue" on these items.

\section{Availability and adequacy of resources}

Parents of children with disabilities reported more often that an environmental resource was "usually not available/adequate" than parents of children without disabilities (table 7). Significant group differences were found for all items except personal transportation. Items showing the largest group differences included programs/services, money, and information.

Parents of children with disabilities also reported less often that a resource was "usually available/adequate" than parents of children without disabilities. Significant group differences were found for all items except for personal and public transportation. Items with the most "usually available/adequate" responses from parents of children with disabilities included personal transportation, equipment/supplies, time, and information. This pattern of findings was similar for parents of children without disabilities, with the exception that these parents tended to report that they usually had money to support their child's participation. In addition, more parents of children without disabilities reported that a particular resource was "not needed" than parents of children with disabilities, with a significant group difference found for public transportation and programs/services.

\section{Discussion}

\section{Participation}

Significant group differences were found on all participation summary scores, indicating that overall, children with disabilities participated less frequently and were less involved in community activities than children without disabilities. These findings are consistent with other studies that have made these comparisons. ${ }^{9,17,35-37}$ Overall, similar results were found at the item level; however, differences attributed to the disability group were not found on some items, particularly items linked to more structured activities (classes/lessons, religious activities, organizationleadership activities, working for pay). In addition, structured community activities had the greatest percentage of children with

Table 7 Differences in community environment items: availability/adequacy of resources

\begin{tabular}{|c|c|c|c|c|c|c|c|c|c|}
\hline \multirow[b]{2}{*}{ Items (n) } & \multicolumn{3}{|c|}{ Usually, No } & \multicolumn{3}{|c|}{ Usually, Yes } & \multicolumn{3}{|c|}{ Not Needed } \\
\hline & $\begin{array}{l}\text { With } \\
\text { Disability }\end{array}$ & $\begin{array}{l}\text { Without } \\
\text { Disability }\end{array}$ & $P^{*}$ & $\begin{array}{l}\text { With } \\
\text { Disability }\end{array}$ & $\begin{array}{l}\text { Without } \\
\text { Disability }\end{array}$ & $P^{*}$ & $\begin{array}{l}\text { With } \\
\text { Disability }\end{array}$ & $\begin{array}{l}\text { Without } \\
\text { Disability }\end{array}$ & $P^{*}$ \\
\hline 1. Personal transportation & $5(2)$ & $4(2)$ & .670 & $180(78)$ & $207(85)$ & .065 & $22(10)$ & $24(10)$ & .921 \\
\hline 2. Public transportation & $67(29)$ & $35(14)$ & .001 & $50(22)$ & $50(20)$ & .739 & $100(43)$ & $148(61)$ & .001 \\
\hline 3. Programs and services & $83(36)$ & $7(3)$ & .001 & $56(24)$ & $150(62)$ & .001 & $26(11)$ & $66(27)$ & .001 \\
\hline 4. Information & $49(22)$ & $6(2)$ & .001 & $90(40)$ & $200(83)$ & .001 & $\mathrm{NA}^{\dagger}$ & NA & NA \\
\hline 5. Equipment and supplies & $51(22)$ & $2(1)$ & .001 & $114(50)$ & $210(87)$ & .001 & NA & NA & NA \\
\hline 6. Time & $42(19)$ & $6(3)$ & .001 & $93(41)$ & $141(59)$ & .001 & NA & NA & NA \\
\hline 7. Money & $54(24)$ & $6(3)$ & .001 & 88 (38) & $170(71)$ & .001 & NA & NA & NA \\
\hline
\end{tabular}

NOTE. Values are $\mathrm{n}(\%)$.

* Based on chi-square analyses (Bonferroni adjustment of the significance level set at $P<.006$ ).

$\dagger \mathrm{NA}$, "Not needed" responses are not provided for these environment items in the PEM-CY. 
and without disabilities who never participated. These findings suggest that greater resources and opportunities might be needed for all school-age children (particularly youth) to participate in structured community activities given the importance of these activities for positive development. ${ }^{1,4}$ Also, these efforts might foster other social opportunities for children with disabilities who are often reported as restricted in their social participation with other children particularly when compared with children without disabilities, as was found in this study. ${ }^{9,11,16}$

Similar and different results have been found in other studies examining patterns of participation of children with disabilities-partially explained by the different samples and measures used in these studies. ${ }^{10,11,13,15,16}$ For example, children with $\mathrm{ABI}$ were found to be most restricted in more structured community events and social activities with peers in the community, possibly because of challenges in behavioral and executive functioning among children with ABI. ${ }^{15,16}$ However, studies of children with $\mathrm{CP}$ and other physical disabilities often report greater participation frequency in structured or formal activities than in informal activities. ${ }^{11,28}$

Children without disabilities were more involved in all activities than were children with disabilities with the exception of working for pay. However, as noted, differences related to disability group were not found in some of the more structured activities (classes/lessons, religious/spiritual activities, organization-leadership activities, working for pay) and both groups of children tended to be least involved in these activities. Other variables including age and income might have partially explained the significant differences found for organizational-leadership activities and working for pay, but this was not examined in this study. Expectations for what is considered acceptable involvement may account for results for religious/spiritual activities given that there was a small effect size attributed to the disability group $\left(n^{2} \mathrm{p}=.04\right)$ for participation frequency here. Simply attending these activities might have been considered acceptable involvement for some of the children with and without disabilities. ${ }^{19}$

Children's enjoyment, preferences, and motivation for activities have been found to be significant predictors of participation $^{28,38}$ and might explain the results related to involvement in structured activities. For example, Heah et al ${ }^{39}$ identified 4 components of "successful participation" experienced by children with disabilities: "having fun," "feeling successful," "doing and being with others," and "doing things by myself." Thus, ensuring that some of these components are experienced during activities might increase a child's involvement in the short term and promote the positive outcomes often associated with these activities later in youth and adulthood., ${ }^{1,4,5}$

Despite the disparities noted, an encouraging result was that children with disabilities were at least moderately involved in activities that they participated in (except for religious/spiritual activities). Thus, measuring the level of involvement may afford new ways to understand and promote participation that is beneficial to children with disabilities because the focus is less on how often they participate and more on the quality of their participation. Considering the child's level of involvement also might point to areas of strength when other indices suggest that participation is restricted or vice versa.

Overall, parents of children with disabilities desired more change in their child's participation than parents of children without disabilities. Parents of children with disabilities desired the most change in unstructured physical activities and getting together with other children in the community-the same areas that had the largest group differences in terms of participation frequency and involvement. Parents of children without disabilities also desired the most change in unstructured physical activities. Both groups of parents may have desired more change in unstructured physical activities so that they could shift some of the responsibilities associated with the managing or planning of these activities to their children. This shifting of responsibilities is part of the developmental process and might also provide parents with some respite and time for other activities. This result also seems to be consistent with the trend in the United States for school-age children to spend more of their discretionary time in sedentary activities (television/videos, computer games) than unstructured physical activities. $^{2,3,40}$ These results have important implications given the significant group disparities found in participation in these activities and the impact this might have on the physical and emotional health and development of all children., ${ }^{1,4,16,40}$

\section{Environment}

Parents of children with disabilities rated environmental factors as barriers more often than parents of children without disabilities. The very large effect size in overall environmental supportiveness summary scores and many of the item-level comparisons in this study point to alarming group disparities. These findings are particularly important given that little, if any, research has been done to compare patterns of environmental factors affecting the participation of children with and without disabilities. Also, parents of children with disabilities in this study reported that key resources (programs and services, information, supplies, and money) were usually unavailable or inadequate-consistent with studies describing environmental barriers specific to children with disabilities. $^{7,15,16,18,20,23,29,31}$

The barriers most frequently reported for children with disabilities focused on the actual features and demands of the activity itself. Although it is unclear how activity features and demands should be classified in the International Classification of Functioning, Disability and Health, ${ }^{24,25}$ other ecological frameworks emphasize the interplay among the person, environment, and activity that enables an individual's participation in activities. ${ }^{41}$ Modification of activity demands and other features of the physical and social environment is a focus of occupational therapy intervention and of strategies reported by parents of children with disabilities to promote participation. ${ }^{15,19,26,42}$ This result, compounded with the very large group difference in environmental supportiveness, suggests that further research is needed to examine the effects of interventions focused on promoting community participation through modification of features of the activity and environment, and/or educating others to do this effectively.

Parents of children with disabilities also rated environmental factors as supports less frequently than parents of children with disabilities, although there were fewer significant group differences here compared with barriers. Some of the largest disparities in supports were similar to those found for barriers (availability/ adequacy of programs/services, information, and equipment/ supplies). However, some of the same areas identified as barriers for some parents of children with disabilities were also identified as supports or as not needed/not an issue for others. These findings highlight the importance of looking beyond barriers and focusing on the interplay of factors that support or hinder community participation. ${ }^{9,15,41,43}$ For example, frequently reported resources identified as "not needed" by parents of children 
with disabilities (eg, personal transportation, equipment/supplies, time, and information) were those that often can be managed by families who have the finances and education needed to acquire them. Given the reported influence of these factors on the participation of children with disabilities, future inquiry is needed to examine whether similar results would be found in families with lower income/education levels as found in families in this study. ${ }^{7,18,23,28,29,31}$

\section{Study limitations}

A key study limitation was the lack of diversity on a number of sociodemographic variables. The majority of families resided in the Northeast, United States, and Southern Ontario, Canada. Income and education levels of the sample were much higher than the median income and education levels in both countries. The race and ethnic backgrounds of the children were primarily white and non-Hispanic, and the study excluded anyone who did not have access to the Internet or could not read and understand English. The results were based on parent/guardian perspectives and might differ if based on children's perspectives. In addition, the research reported in this article did not investigate other key variables that also might have influenced patterns of community participation, supports, and barriers for children with disabilities, such as diagnosis and type and severity of impairment.

\section{Conclusions/future directions}

This study described patterns of community participation and environmental supports and barriers for a large number of schoolage children from the United States and Canada. Results provide insights about where greater efforts might be needed to promote community participation of school-age children with a wide range of disabilities. However, generalization to the broader population of children with and without disabilities is not possible. Future study is recommended to examine the direct and indirect effects of other variables (eg, age, sex, family income and education levels, geographic region) that might influence patterns of community participation and environment supports and barriers in a more representative sample. Further research is underway to examine the influence of type and severity of disabling conditions on participation and environmental factors specifically for the children and youth with disabilities in this sample.

\section{Keywords}

Children; Community; Environment; Social participation; Rehabilitation

\section{Corresponding author}

Gary Bedell, PhD, Dept of Occupational Therapy, Tufts University, 26 Winthrop St, Medford, MA 02155. E-mail address: gary. bedell@tufts.edu.

\section{References}

1. Eccles JS, Barber BL, Stone M, Hunt J. Extracurricular activities and adolescent development. J Soc Iss 2003;59:865-89.
2. Larson RW. Toward a psychology of positive youth development. Am Psychol 2000;55:170-83.

3. Larson RW, Verma S. How children and adolescents spend time across the world: work, play, and developmental opportunities. Psychol Bull 1999;25:701-36.

4. Mahoney JL, Cairns BD, Farmer TW. Promoting interpersonal competence and educational success through extracurricular activity participation. J Educ Psychol 2003;95:409-18.

5. Rutter M. Psychosocial resilience and protective mechanisms. Am J Orthopsychiatry 1987;57:316-31.

6. Coster W, Khetani MA. Measuring participation of children with disabilities: issues and challenges. Disabil Rehabil 2008;30:639-48.

7. King G, Law M, King S, Rosenbaum P, Kertoy MK, Young NL. A conceptual model of the factors affecting the recreation and leisure participation of children with disabilities. Phys Occup Ther Pediatr 2003;23:63-90

8. Law M. Participation in the occupations of everyday life. Am J Occup Ther 2002;56:640-9.

9. Bedell G. Further validation of the Child and Adolescent Scale of Participation (CASP). Dev Neurorehabil 2009;12:342-51.

10. Michelsen SI, Flachs EM, Uldall P, et al. Frequency of participation of 8-12-year-old children with cerebral palsy: a multi-centre crosssectional European study. Eur J Paediatr Neurol 2009;13:165-77.

11. Imms C, Reilly S, Carlin J, Dodd K. Diversity of participation in children with cerebral palsy. Dev Med Child Neurol 2008;50:363-9.

12. Majnemer A, Shevell M, Law M, et al. Participation and enjoyment of leisure activities in school-aged children with cerebral palsy. Dev Med Child Neurol 2008;50:751-8.

13. Orlin M, Palisano R, Chiarello L, et al. Participation in home, extracurricular, and community activities among children and young people with cerebral palsy. Dev Med Child Neurol 2010;52:160-6.

14. King G, Law M, Hurley P, Petrenchik T, Schwellnus H. A developmental comparison of the out-of-school recreation and leisure activity participation of boys and girls with and without physical disabilities. Int J Disabil Dev Educ 2010;57:77-107.

15. Bedell GM, Dumas HM. Social participation of children and youth with acquired brain injuries discharged from inpatient rehabilitation: a follow-up study. Brain Inj 2004;18:65-82.

16. Galvin J, Froude EH, McAleer J. Children's participation in home, school and community life after acquired brain injury. Aust Occup Ther J 2010;57:118-26.

17. Law M, Anaby D, DeMatteo C, Hanna S. Participation patterns of children with acquired brain injury. Brain Inj 2011;25:587-95.

18. Law M, Petrenchik T, King G, Hurley P. Perceived environmental barriers to recreational, community, and school participation for children and youth with physical disabilities. Arch Phys Med Rehabil 2007;88:1636-42.

19. Bedell GM, Khetani MA, Cousins MA, Coster WJ, Law MC. Parent perspectives to inform development of measures of children's participation and environment. Arch Phys Med Rehabil 2011;92: 765-73.

20. Colver A, Dickinson H, Parkinson K, et al. Access of children with cerebral palsy to the physical, social and attitudinal environment they need: a cross-sectional European study. Disabil Rehabil 2011;33:28-35.

21. DeMatteo CA, Cousins MA, Lin CY, Law MC, Colantonio A, Macarthur C. Exploring postinjury living environments for children and youth with acquired brain injury. Arch Phys Med Rehabil 2008; 89:1803-10.

22. Hammal D, Jarvis SN, Colver AF. Participation of children with cerebral palsy is influenced by where they live. Dev Med Child Neurol 2004;46:292-8.

23. Mihaylov SI, Jarvis SN, Colver AF, Beresford B. Identification and description of environmental factors that influence participation of children with cerebral palsy. Dev Med Child Neurol 2004; 46:299-304.

24. World Health Organization. International Classification of Functioning, Disability and Health. Geneva, Switzerland: World Health Organization; 2001. 
25. World Health Organization. International Classification of Functioning, Disability and Health - Children and youth version. Geneva, Switzerland: World Health Organization; 2008.

26. Bedell G, Cohn E, Dumas H. Exploring parents' use of strategies to promote social participation in school-age children with acquired brain injuries. Am J Occup Ther 2005;59:273-84.

27. Welsh B, Jarvis S, Hammal D, Colver A. North of England Collaborative Cerebral Palsy Survey. How might districts identify local barriers to participation for children with cerebral palsy? Public Health 2006;120:167-75.

28. King G, Law M, Hanna S, et al. Predictors of the leisure and recreation participation of children with physical disabilities: a structural equation modeling analysis. Children's Health Care 2006;35:209-34.

29. Law M, King G, King S, et al. Patterns of participation in recreational and leisure activities among children with complex physical disabilities. Dev Med Child Neurol 2006;48:337-42.

30. Finch N, Lawton D, Williams J, Sloper P. Disability Survey 2000: young people with a disability and sport. London: Sport England; 2001.

31. Sloper T. Families with disabled children: social and economic needs are high but remain largely unmet. Br Med J 2006;333:928-9.

32. Coster W, Bedell G, Law M, et al. Psychometric evaluation of the Participation and Environment Measure for Children and Youth (PEM-CY). Dev Med Child Neurol 2011;53:1030-7.

33. Coster W, Law M, Bedell G, Khetani M, Cousins M, Teplicky R. Development of the Participation and Environment Measure for Children and Youth: conceptual basis. Disabil Rehabil 2012;34: 238-46.
34. Kirk RE. Experimental design: procedures for the behavioral sciences. Vol. 3. Pacific Grove: Brooks/Cole; 1995.

35. Engel-Yeger B, Jarus T, Anaby D, Law M. Differences in patterns of participation between youths with cerebral palsy and typically developing peers. Am J Occup Ther 2009;63:96-104.

36. Hilton CL, Crouch MC, Israel H. Out-of-school participation patterns in children with high-functioning autism spectrum disorders. Am J Occup Ther 2008;62:554-63.

37. Brown M, Gordon WA. Impact of impairment on activity patterns of children. Arch Phys Med Rehabil 1987;68:828-32.

38. Majnemer A, Shevell M, Law M, Poulin C, Rosenbaum P. Level of motivation in mastering challenging tasks in children with cerebral palsy. Dev Med Child Neurol 2010;52:1120-6.

39. Heah T, Case T, McGuire B, Law M. Successful participation: the lived experience of children with disabilities. Can J Occup Ther 2007; 74:38-47.

40. Strong WB, Malina RM, Blimkie CJ, et al. Evidence based physical activity for school-age youth. J Pediatr 2005;146:732-7.

41. Mallinson T, Hammel J. Measurement of participation: intersecting person, task, and environment. Arch Phys Med Rehabil 2010;91: S29-33.

42. Gallimore R, Weisner TS, Bernheimer LP, Guthrie D, Nihira K. Family responses to young children with development delays: accommodation activity in ecological and cultural contexts. Am J Ment Retard 1993;98:185-206.

43. Law M, Cooper B, Strong S, Stewart D, Rigby P, Letts L. Personenvironment-occupation model: a transactive approach to occupational performance. Can J Occup Ther 1996;63:9-23. 